\title{
Severity of Disability and Income as Predictors of Parents' Satisfaction with Their Family Quality of Life During Early Childhood Years
}

\author{
Mian Wang, Ann P. Turnbull, Jean Ann Summers, Todd D. Little, Denise J. Poston, \\ Hasheem Mannan, and Rud Turnbull \\ Beach Center on Disability, The University of Kansas
}

The field of early intervention has recognized a growing need to study contributing factors of family outcomes such as family quality of life (FQOL). This study of 130 fathers and 234 mothers of families in early childhood programs explores the associations between family income and severity of disability, and fathers' and mothers' satisfaction with their $F Q O L$. The results reveal that severity of disability is a significant predictor of fathers' and mothers' satisfaction ratings of FQOL; that family income is a significant predictor of mothers' satisfaction ratings of their FQOL, but not of fathers; and that there is no interaction effect of family income and severity of disability with respect to fathers' and mothers' satisfaction ratings of $F Q O L$.

DESCRIPTORS: parents' satisfaction, family quality of life, income, predictors, early childhood

\section{Introduction}

\section{Defining Family Outcomes}

The field of early intervention has the purpose of supporting young children with disabilities and their families (Dunst \& Bruder, 2002; Guralnick, 1997). The task of supporting families requires that the field define and measure outcomes that families might expect to experience from early intervention (Bailey et al., 1998). In the past, one conceptualization of the impact of services on families was a reduction of stress, and typical measures included the Parenting Stress Index (Abidin, 1995) or the Questionnaire on Resources and Stress (Friedrich, Greenberg, \& Crnic, 1983). Another conceptualization of family impact was that services should enhance natural supports available to families; these led to measures such as the Support Functions Scale (Dunst \& Trivette, 1988) or the Family Support Scale (Dunst, Jenkins, \& Trivette, 1984). Still other conceptualizations considered family outcomes in terms of marital adjustment (as in the Dyadic Adjustment Scale [Spanier, 1976]) or in terms of parents' satisfaction with services for their children (e.g., the Client Satisfaction Questionnaire [Larsen, Atkisson, Hargreaves, \&
Nguyen, 1979]) or satisfaction with the processes of care (e.g., the Family-Focused Intervention Scale [Mahoney, O'Sullivan, \& Dennebaum, 1990] or the Measure of Processes of Care [King, Rosenbaum, \& King, 1996]).

Recently, a more comprehensive view of family outcomes was proposed by Bailey et al. (1998) in the form of a framework presenting eight types of expected outcomes of early intervention on families: (a) a family's perception of how early intervention makes a difference in the child's life, (b) a family's perception of how early intervention makes a difference in the family's life, (c) a family's positive view of service providers and the service system, (d) the impact of early intervention on helping children grow, learn, and develop, (e) the impact of early intervention on parents' advocacy and their ability to work with professionals, (f) the impact of early intervention on building a strong support system for the family, ( $g$ ) the impact of early intervention on the program promoting the family's optimistic view of the future, and (h) impact of early intervention on enhancing the family's perceived quality of life. The latter outcome, family quality of life [FQOL], is the focus of this paper.

\section{Measuring $\mathrm{FQOL}$}

Based on a national survey exploring valued outcomes of service coordination, early intervention, and natural environments, Dunst and Bruder (2002) reported that family satisfaction and improved FQOL were the most valued outcomes as determined by practitioners, administrators, and parents. However, Bailey et al. (1998) noted that efforts to measure FQOL present a "formidable challenge" (p. 323) to the field, given that FQOL studies are still in their infancy. Especially in echoing the concerns of Heal and Sigelman (1990), Bailey et al. (1998) pointed out, "Variables that could threaten validity or reliability of quality of life measures include how the data are collected, how questions are phrased, characteristics of the interviewer, and characteristics of the respondents" (p. 323). 
Two research programs have been active over the past several years in conceptualizing and measuring FQOL, including Brown et al. (2003) and work at the Beach Center on Disabilities (Park et al., 2003; Poston et al., 2003; Turnbull, Marquis, Hoffman, Poston, Mannan, Wang, et al., 2004). Brown et al. (2003) developed a survey instrument (Family Quality of Life Questionnaire) that collects both quantitative and qualitative information from families with respect to four facets: $o p$ portunities for participation, initiative in taking advantage of opportunities, attainment in accomplishing things important to them, and satisfaction in nine areas of family life: health, financial well-being, family relationships, support from other people, support from services, careers and preparing for careers, spiritual and cultural life, leisure, and community and civic involvement. The researchers indicated that the measure was developed over a 3-year period by an international group of experts (some of whom have a history of conducting quality of life research with individuals with disabilities). No information, however, about the psychometric properties of the instrument was reported.

The Beach Center research program has produced a quantitative measurement tool, the Beach Center Family Quality of Life Scale (Park et al., 2003; Poston et al., 2003; Turnbull et al., 2004). The development of this scale has proceeded through three phases. Phase 1 involved a comprehensive qualitative research study in which 33 focus groups and 34 individual interviews were carried out with 187 family members of children with a disability, individuals with a disability, family members of children without a disability, service providers, and administrators (Poston et al., 2003). In the second phase, the domains and indicators of FQOL derived from the qualitative study were tested in a national study involving 1,197 respondents from 459 families (Park et al., 2003). The third phase involved collecting responses from an additional 488 families to test the factor structure of the FQOL construct. The five factors that emerged were family interaction, parenting, emotional well-being, physical/material well-being, and disability-related support. The five factors were found to be unidimensional and internally consistent with acceptable psychometric properties (as will be described below).

\section{Family Characteristics Mitigating Impacts of Intervention on FQOL}

As Bailey et al. (1998), have noted, assessment of early intervention on FQOL is likely to be mitigated by a variety of other factors, including characteristics of the family. This study examines the potential impact on FQOL of two family characteristics: family income and the severity of the child's disability. To our knowledge, there have been no studies focused on the relationship between these two family characteristics and FQOL. However, there are studies focusing on the impact of these characteristics on other family outcomes, which both guide a rationale for selection of these variables for our study and provide a framework for hypothesizing their relationship to FQOL. The following is a brief review of this literature.

Low income has been found to have multiple impacts on family outcomes. Elder, Nguyen, and Caspi (1985) found that poverty limited parents' capacity for positive family interaction, as reflected by parents showing less sensitivity and satisfaction with parenting and more frequent use of aversive, coercive discipline methods. Families with a lower socioeconomic status are at higher risk for significant family or marital discord (Beiderman, Miberger, Faraone, Kiely, Guite, Mick, et a1., 1995; Shaw \& Emery, 1987; Vickers, 1994; Vosler, Green, \& Kolevzon, 1987; Willoughby \& Glidden, 1995). Families from poverty backgrounds tend to have a higher incidence of substance abuse and exposure to violence, both in the home and in their neighborhoods (Hanson \& Carta, 1996; Park, Turnbull, \& Tumbull, 2002).

Conversely, Scorgie, Wilgosh, and McDonald (1998) found that families with higher incomes have more choices available to help them cope and also showed higher paternal and maternal satisfaction. In addition, research has shown that higher income helps families cope with extra health and daily living demands of their child with a disability and contributes to parental adaptability (Yau and Li-Tsang, 1999). Turnbull and Turnbull (2001) pointed out that families with a higher socioeconomic status have more resources available to deal with issues related to their child's disabilities than do families who have a lower socioeconomic status.

Regarding the variable of the impact of the severity of a child's disability on families, the key aspect of severity that has received the most attention is the impact of more severe behavior problems (as contrasted to less severe behavior problems) on family outcomes. The severity of behavior problems has been shown to be associated with lower levels of family well-being during the early childhood years (Baker et al., 2003), elementary and secondary school years (Floyd \& Gallagher, 1997), and middle adulthood years (Essex, Seltzer, \& Krauss, 1999).

Aside from the extent of behavior problems, research is mixed on the association of severity of disability with family outcomes. Research supporting an association of severity of disability with increased maternal stress and/or burden has been reported during the early childhood years (Hanson \& Hanline, 1990; McKinney \& Peterson, 1987), elementary and secondary years (Blacher, Nihira, \& Meyers, 1987; Donovan, 1988), and middle adulthood years (Seltzer \& Krauss, 1989). An additional study that included children of early childhood and elementary years also reported that children's lower communication skills were related to higher levels of family stress (Frey, Greenberg, \& Fewell, 1989). 
In contrast, Kazak and Clark (1986) reported that marital satisfaction was higher in families of children with more severe spina bifida compared with children who experienced milder spina bifida. Bristol, Gallagher, and Schopler (1988) found that severity level was unrelated to maternal depression, and Haldy and Hanzlik (1990) reported that severity of retardation was unrelated to maternal competence.

Previous research has not specifically addressed the interaction of income and severity in terms of family outcomes. Fujiura and Yamaki (2000) pointed out that little is known precisely about the intervening dynamics between family socioeconomic status and children's disability despite the findings of the covariation of poverty and disability in their study. In particular, much remains unknown about whether and how a family's socioeconomic status (income) may interact with the severity of the child's disability in affecting FQOL. Therefore, further research is required to provide empirical evidence that addresses the causal relationships between these family demographic variables and FQOL.

\section{Purposes of This Research}

The purposes of this study were (a) to examine whether family income predicts both fathers' and mothers' satisfaction with their FQOL; (b) to examine whether severity of disability predicts both fathers' and mothers' satisfaction with their FQOL; and (c) to determine whether there is an interaction effect of family income and severity of disability as a combination for predicting both fathers' and mothers' satisfaction with their FQOL. We specifically examined the following research questions:

1. Does family income positively predict fathers' and mothers' satisfaction with their FQOL?

2. Does severity of the child's disability negatively predict fathers' and mothers' satisfaction with their FQOL?

3. Is there an interaction effect of family income and severity of disability for predicting fathers' and mothers' satisfaction with their FQOL?

\section{Method}

\section{Sampling and Procedure}

A stratified sampling approach was used to select families who have young children with special needs served in the early childhood programs (e.g., Part B and C) in terms of variables of geographic locations (e.g., regions) and community types where families live (e.g., urban, suburban, and rural areas). In four regions (North, South, West, and East) of Kansas, we sought collaboration of Part B and C early childhood agencies to help recruit participating families by considering the factors of marital status and ethnic diversity. About 80 agencies (both Part $B$ and $C$ ) in the four regions were first contacted by phone. In the calls, we provided a brief description of the study and asked them to consider participating. Follow-up phone calls were made after 2 weeks to obtain their decision. A total of 30 programs initially expressed interest in participation. A packet that included a cover letter, an introduction to the study, and a short version of the research proposal was then sent to them. Of 30 programs that initially expressed interest, 13 programs ( $43 \%$ ) eventually decided to participate in the study. Among those, four programs provided services to children ages 0 to 5 (i.e., Part B and C), four to children ages 0 to 3 (i.e., only Part $\mathrm{C}$ ), and five to children ages 3 to 5 (i.e., only Part B).

We asked the program staff for information about the number of families served in their programs, the possible number of families who might participate in the study, and their preferences about distributing the packets. We sent a sufficient number of survey packets to the participating agencies for all families served to receive a packet. Each packet contained both "Dad" and "Mom" verions" of the FQOL scale (Turnbull et al., 2004) including 25 items and 15 demographic questions, a return envelope, and the instructions for the family to mail the completed forms back to the researchers. In addition, we made site visits to five programs to collect surveys. In cooperation with the agencies, we organized a "Family Night" event in which the families were invited to attend the event and bring in their completed surveys. Those families who had not yet completed the surveys were also invited to attend the event. They were given the option of either attending a group administration on the site during the event or mailing the completed surveys later. Food and drinks were provided during the event, and a family photo was taken for each participant family as a gift.

\section{Participants}

A total of 1,409 families received the survey packets. Four hundred eleven individual respondents from 280 families returned the completed surveys. The response rate is $19.87 \%$. Of the 280 families who returned the surveys, respondents consisted of $266(95 \%)$ biological, foster, or adoptive parents and $7(2.5 \%)$ grandparents and other relatives (note that there are 7 missing responses, $2.5 \%$ ). We excluded the seven grandparents' or other relative's responses from the analysis, given that the focus of this study was to examine the predictive ability of family income and severity of disability for fathers' and mothers' FQOL. Therefore, the data of 130 fathers and 234 mothers, out of 280 families, were

"The "Dad" and "Mom" versions of the FQOL scale were designated for use by father and mother respondents, respectively. The "Dad" version had a stamp of "Dad" on the cover of the scale and the "Mom" version had a stamp of "Mom" on the cover. However, the FQOL scale items were identical in the "Dad" and "Mom" versions. 
analyzed. Table 1 presents family demographic information of 280 families primarily based on mothers' demographic responses (fathers' responses were used for a few families when mothers' responses were unavailable). The disabilities of the children whose families participated in the study included ADD/ADHD (2\%), autism spectrum disorder (4\%), developmental delays $(14 \%)$, emotional or behavioral disorder $(1 \%)$, hearing impairments $(1 \%)$, mental retardation $(6 \%)$, physical disabilities $(3 \%)$, speech or language impairments $(49 \%)$, vision impairments $(1 \%)$, health impairments $(4 \%)$, and no specific diagnostics $(10 \%)$.

\section{Measures}

The survey packet contained the Beach Center Family Quality of Life (FQOL) Scale and demographic questions. The FQOL scale is designed to measure families' perceptions of both the importance of differ-

Table 1

Participant Family Demographics

\begin{tabular}{|c|c|c|}
\hline Variables & $\mathrm{N}$ & $\%$ \\
\hline \multicolumn{3}{|l|}{ Ethnic Background } \\
\hline White Hispanic & 8 & 2.9 \\
\hline White Non-Hispanic & 221 & 78.9 \\
\hline American Indian or Alaskan Native & 6 & 2.1 \\
\hline Asian or Pacific Islander & 7 & 2.5 \\
\hline Black or African American & 8 & 2.9 \\
\hline Other & 26 & 9.3 \\
\hline Missing & 4 & 1.4 \\
\hline \multicolumn{3}{|l|}{ Age of Child with a Disability } \\
\hline $0-3$ years & 187 & 66.8 \\
\hline $4-8$ years* & 81 & 28.9 \\
\hline Missing & 12 & 4.3 \\
\hline \multicolumn{3}{|l|}{ Level of Severity of Disability } \\
\hline Mild & 143 & 51.1 \\
\hline Moderate & 57 & 20.4 \\
\hline Severe & 25 & 8.9 \\
\hline Very severe & 8 & 2.9 \\
\hline Unknown & 34 & 12.1 \\
\hline Missing & 13 & 4.6 \\
\hline \multicolumn{3}{|l|}{ Total Household Income } \\
\hline Less than $\$ 13,999$ & 27 & 9.6 \\
\hline Between $\$ 14,000$ and $\$ 17,999$ & 19 & 6.8 \\
\hline HBetween $\$ 18,000$ and $\$ 21,999$ & 17 & 6.1 \\
\hline Between $\$ 22,000$ and $\$ 26,999$ & 14 & 5.0 \\
\hline Between $\$ 27,000$ and $\$ 34,999$ & 35 & 12.5 \\
\hline Between $\$ 35,000$ and $\$ 41,999$ & 21 & 7.5 \\
\hline Between $\$ 42,000$ and $\$ 54,999$ & 27 & 9.6 \\
\hline Between $\$ 55,000$ and 64,999 & 16 & 5.7 \\
\hline Between $\$ 65,000$ and $\$ 74,999$ & 27 & 9.6 \\
\hline Over $\$ 75,000$ & 55 & 19.6 \\
\hline Missing & 22 & 7.5 \\
\hline \multicolumn{3}{|l|}{ Community Type } \\
\hline Large city or metropolitan area $(>200,000)$ & 69 & 24.6 \\
\hline Urbanized area $(50,000-200,000)$ & 63 & 22.5 \\
\hline Town or small city $(2,500-50,000)$ & 99 & 35.4 \\
\hline Rural area or town $(<2,500)$ & 37 & 13.2 \\
\hline Missing & 12 & 4.3 \\
\hline
\end{tabular}

* This study included some aged 6-8 children who were still in Part B programs ent aspects of family quality life as well as their level of satisfaction with their quality of life (Turnbull et al., 2004). It contains 25 items in five subscales: Family Interaction ( 6 items), Parenting (6 items), Emotional Well-being (4 items), Physical/Material Well-Being (5 items), and Disability-Related Support (4 items). Table 2 presents the description of the above five subscales and a few sample questions (i.e., items). The FQOL scale is rated on a 5-point Likert-type scale with each item rated on importance as well as satisfaction.

Turnbull et al. (2004) reported the psychometric properties of the FQOL scale, indicating that the overall FQOL model (tested at the subscale level) had excellent fit, $\chi^{2}(5)=3.41, p=.63, \mathrm{CFI}=1.00$, RMSEA $=.00$, and Cronbach's alpha for the scale was .94 . It was also reported that each of the five subscales was shown to be unidimensional and internally consistent: Family Interaction (alpha $=92$ ), Parenting (alpha = .88 ), Emotional Well-Being (alpha $=.80$ ), Physical/ Material Well-Being (alpha $=.88$ ), and DisabilityRelated Support (alpha $=.92$ ) (Turnbull et al., 2004).

In the FQOL scale, there are demographic questions with respect to family income, education level of parents, ethnicity, and severity of children's disability. 'The family income question includes 10 categories ranging from less than $\$ 13,999$ to over $\$ 75,000$. The question of severity of children's disability includes four levels: mild, moderate, severe, and very severe.

\section{Data Analysis}

Only fathers' and mothers' satisfaction ratings with respect to the five FQOL subscales were used in the analysis of this study, although the data of their importance ratings of the five FQOL subscales were also collected through the administration of the FQOL scale. Research has shown that families who have different incomes and have children with different degrees of disabilities do not rate differently the importance of their FQOL (Park, 2001). Poston et al. (2003) pointed out that the fundamental components of FQOL (e.g., items of the FQOL scale) were commonly viewed as important by respondents from families with different demographic features (e.g., income, ethnicity, and severity of children's disabilities). Therefore, we decided to exclude the importance ratings of FQOL in the analysis of this study.

We used the technique of structural equation modeling (SEM) to test the hypothesized models with respect to the associations between family demographic variables (e.g., family income and severity of child's disability) and parents' ratings of their satisfaction with FQOL in this study. We used the LISREL 8 program, developed by Joreskog and Sorbom (1993), to analyze fathers' and mothers' data for testing our assumption about the effects of family income and severity of child's disability and their possible interaction in pre- 
Table 2

Description of FQOL Subscales and Sample Questions

For my family to have a good life together, how satisfied am I that....

Family Interaction: the relationships among family members.

My family enjoys spending time together.

My family is able to handle life's ups and downs.

My family members show that they love and care for each other.

Parenting: the activities that adult family members do to help children grow and develop.

Family members help the children with schoolwork and activities.

Family members teach the children how to get along with others.

Family members help the children learn to be independent.

Emotional Well-Being: the emotional health and resources to meet the family's needs.

My family has the support we need to relieve stress.

My family members have some time to pursue individual interests.

My family has outside help available to us to take care of special needs of all family members.

Description of FQOL subscales and sample questions

PhysicaiMaterial Well-Being: the physical health, environment, and resources to meet the family's needs.

My family gets medical care when needed.

My family members have transportation to get to the places they need to be.

My family has a. way to take care of our expenses.

Disability-Related Support: the support to meet the needs of the family member with a disability.

My family member with special needs has support to make progress at school.

My family member with special needs has support to make progress at home.

My family member with special needs has support to make friends.

dicting satisfaction with FQOL. We used SEM because the primary construct of interest, FQOL, is represented by multiple indicators. SEM procedures estimate the latent variable in a manner that corrects for the unreliability of measurement (Byrne, 1998). Moreover, in our comparisons of mothers versus fathers, SEM procedures allow us to assess the measurement equivalence of the constructs across mothers and fathers as well as to make direct statistical comparisons of similarities and differences in the means, variances, and regression relationships among the constructs (Little, 1997; Meredith, 1993). We tested the hypothesized models sequentially in four steps: (a) a test of the measurement model that specifies the relations between observed variables (measures of the model variables) and unobserved variables (latent variables), (b) a test of the measurement equivalence of these relationships across mothers and fathers, (c) a test of the homogeneity of the variances of the constructs across mothers and fa- thers, and (d) a test of the structural model (i.e., path model) that specifies the causal relationship between the latent constructs (e.g., FQOL, family income, and severity of disability in this study; Byrne, 1998; Kline, 1998).

Figure 1 presents the hypothesized model that was tested across fathers and mothers. There are four latent constructs. The latent construct of family income contains only one indicator (total household income), as does the latent construct of severity (severity of child's disability). The latent construct of interaction also contains only one indicator (interaction term). The interaction term was the orthogonalized product of family income and severity of child's disability (see Aiken \& West, 1991; Little, Hoffman, Bovaird, \& Widaman, 2004). The latent construct of FQOL contains five indicators that are based on the underlying FQOL construct identified in previous research (Turnbull et al., 2004). 


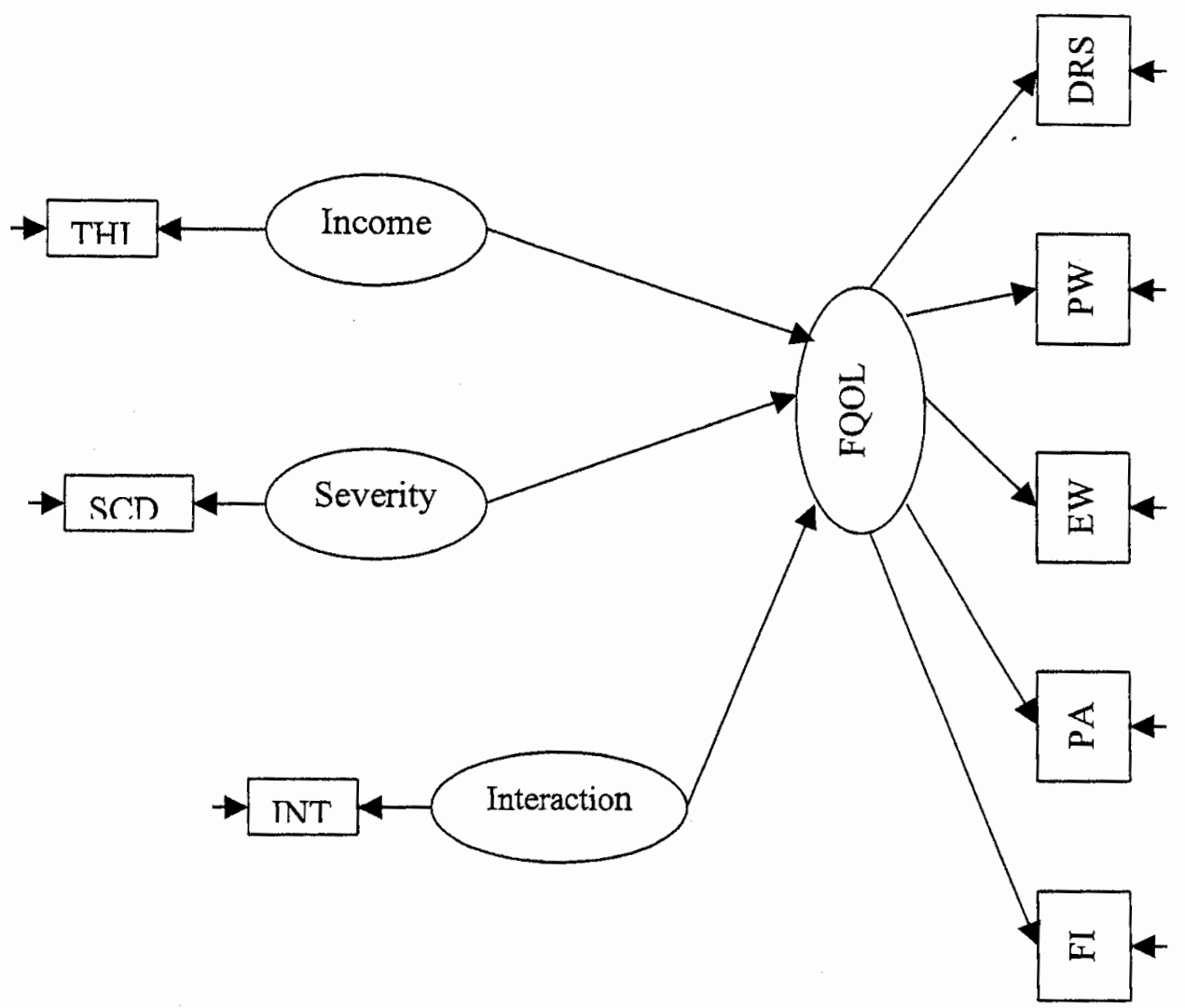

Figure 1. Hypothesized model for income, severity, and interaction effect of income and severity as predictors of parents' satisfaction with their FQOL.

\section{Results}

We focused on examining three research questions with respect to predictive nature of family income and severity of child's disability on parents' satisfaction with their FQOL and interaction effect of family income and severity of disability for predicting parents' satisfaction with their FQOL. In correspondence with these research questions, we present the analysis results in three steps: (a) examination of the correlations among latent variables separately for fathers and mothers, (b)

Table 3

Pearson Correlations Among the Measured Variables

\begin{tabular}{|c|c|c|c|}
\hline Latent Variables & 1 & 2 & 3 \\
\hline $\begin{array}{l}\text { A. Fathers }(n=130) \\
\text { 1. Family income } \\
\text { 2. Severity of child's disability } \\
\text { 3. Satisfaction with family } \\
\text { quality of life (FQOL) }\end{array}$ & $\begin{array}{l}1.00 \\
.129 \\
.151\end{array}$ & $\begin{array}{l}1.00 \\
-.348 * *\end{array}$ & 1.00 \\
\hline $\begin{array}{l}\text { B. Mothers }(\mathrm{n}=234) \\
\text { 1. Family income } \\
\text { 2. Severity of child's disability } \\
\text { 3. Satisfaction with family } \\
\text { quality of life (FQOL) }\end{array}$ & $\begin{array}{l}1.00 \\
-.290^{*} *\end{array}$ & $\begin{array}{l}1.00 \\
-.375^{* *}\end{array}$ & 1.00 \\
\hline
\end{tabular}

${ }^{*} \mathrm{p}<.05 ;{ }^{* *} \mathrm{p}<.01$. report of the test of measurement model that examines the adequacy of manifest variables as indicators of their respective latent constructs for the groups of fathers and mothers, and (c) presentation of the models comparing fathers and mothers in predicting fathers' and mothers' satisfaction with their FQOL.

\section{Initial Relations of Manifest Variables}

There were three measured variables in this study: family income, severity of child's disability, and FQOL. Correlations among the three measured variables for fathers are presented in Table 3, part A, and for mothers in Table 3, part B. For fathers, severity of disability is negatively associated with their satisfaction ratings of FQOL $(r=-.348, p<.01)$. Family income is not significantly correlated with fathers' satisfaction ratings of FQOL $(r=.151, p>.05)$. For mothers, family income is significantly correlated with their satisfaction ratings of FQOL $(r=.299, p<.01)$. Severity of disability is negatively associated with mothers' satisfaction ratings of FQOL $(r=.375, p<.01)$. Further analyses based on the SEM framework were conducted to examine whether severity of disability and family income are significant predictors for fathers' and mothers' satisfaction with their FQOL. 


\section{Measurement Model: Testing Measurement Equivalence}

As mentioned, we addressed three research questions in this study. Before examining the structural models to answer these questions, it is necessary to test their measurement models. Figure 1 presents the hypothesized model with respect to the three research questions. We examined the measurement model as a two-group mean and covariance structures model to examine the measurement equivalence of the constructs across both mothers and fathers (Little, 1997; Meredith, 1993).

The measurement model included four latent constructs. The construct of family income, severity, and their interaction are represented by only one observed variable, respectively. The FQOL construct, on the other hand, was represented by five indicators (the FQOL subscales): Family Interaction, Parenting, Emotional Well-Being, Physical/Material Well-being, and Disability-Related Support. The two indicators Family Interaction and Parenting both assess the interpersonal dynamics of FQOL, and therefore we anticipated that the residual of these two indicators may correlate with one another.

The initially estimated model did, indeed, suggest a correlated residual between Family Interaction and Parenting in both mothers and fathers. In addition, there was an indication of an additional relationship between Income and Physical/Material Well-Being, above and beyond the relationship between Income and FQOL. With the addition of these two estimates in both the mothers' and the fathers' groupings, the freely estimated CFA showed very good levels of fit, $\chi^{2}(34 \mathrm{n}=345)=57.3, p<.001, \mathrm{RMSEA}=.062, \mathrm{CFI}=$ $.96, \mathrm{NNFI}=.97$.

We next tested the measurement equivalence of the constructs across mothers and fathers. Specifically, following standard procedures (Little, 1997; Meredith, 1993), we equated the loadings and intercepts of the indicators across mothers and fathers. This model revealed no significant difference in fit when compared with the initial, freely estimated (i.e., no estimated cross-group constraints), model, $\Delta \chi^{2}\left(9_{\mathrm{n}}=345\right)=10.5, p$ $>.25$. Moreover, the model fit statistics showed slight improvements in fit, $\mathrm{RMSEA}=.057, \mathrm{CFI}=.97, \mathrm{NNFI}$ $=.98$. Both of these results strongly indicate that FQOL is measurement invariant when rated by both mothers and fathers.

We also tested the homogeneity of the variances of the latent constructs. This model, too, revealed no differences between mothers and fathers, $\Delta \chi_{(4, n=345)}^{2}=$ $12.2, p>.50$, indicating that mothers and fathers were equally distributed in their ratings of FQOL. This finding also enables us to compare directly the strength of the regression relationships between income, severity, their interaction, and FQOL.

Before turning to the tests of the structural relation- ships, however, we examined the means of the latent constructs across mothers and fathers; that is, because the test of measurement equivalence included the intercepts of the indicators, it was also possible to evaluate the constructs for mean-level differences between mothers and fathers. The results indicate that the fathers rated FQOL slightly higher than mothers. Specifically, the latent mean revealed a .25 standard unit difference that was higher for fathers compared with mothers $(z=2.02, p<.05)$.

\section{Structural Models}

Figure 1 presents the hypothesized model in which family income, rated severity of child's disability, and the interaction effect of family income and severity of disability are posited as predict parents' satisfaction with their FQOL. The tests of our hypotheses revealed that in both mothers and fathers, income was a weak predictor of FQOL only for mothers $(\beta=.17, z=2.17$, $p<.05)$, indicating that mothers with higher levels of income rated FQOL higher than mothers with lower levels of income. In fathers, the effect was nonsignificant ( $\beta=.06, z=0.63, p>.25)$. For severity, on the other hand, the effect on FQOL was pronounced $(\beta=$ $-.38, z=3.91, p<.01$ for mothers and $\beta=-.39, z=$ $3.95, p<.01$ for fathers). In terms of the expected interaction between income and severity, we did not find support. In both mothers and fathers the interaction was nonsignificant $(\beta=.07, z=0.96, p>.25$ for mothers and $\beta=.05, z=0.50, p>.25$ for fathers). These two effects were therefore removed from the final model. We also tested the significance of the difference in the effect of severity on FQOL in mothers and fathers: the effects did not differ, $\left.\Delta \chi_{(1, \mathrm{n}}^{2}=345\right)=0.01, p$ $>.50$. The final model, presented in Figure 2, explained $17 \%$ of the variance in FQOL for mothers and $16 \%$ of the variance in FQOL for fathers.

\section{Discussion}

The purpose of this study was to explore the associations between family income and severity of disability and fathers' and mothers' satisfaction with their FQOL while their children were receiving early childhood special services. The discussion will be focused on (a) limitations of the study, (b) summary of findings, (c) implications for future research, and (d) implications for policy and practice.

\section{Limitations of the Study}

One of the limitations of this study is the limited representativeness of our sample with regard to the variables of family income and severity of disability. Our sample has $17 \%$ fathers in the lower income group (less than $\$ 25,000$ per year), $37 \%$ in the middle income group ( $\$ 25,000-\$ 55,000)$, and $46 \%$ in the high-income group (above $\$ 55,000$ ). For the mothers in our sample, there are $28 \%$ mothers in the lower income group, 33\% 


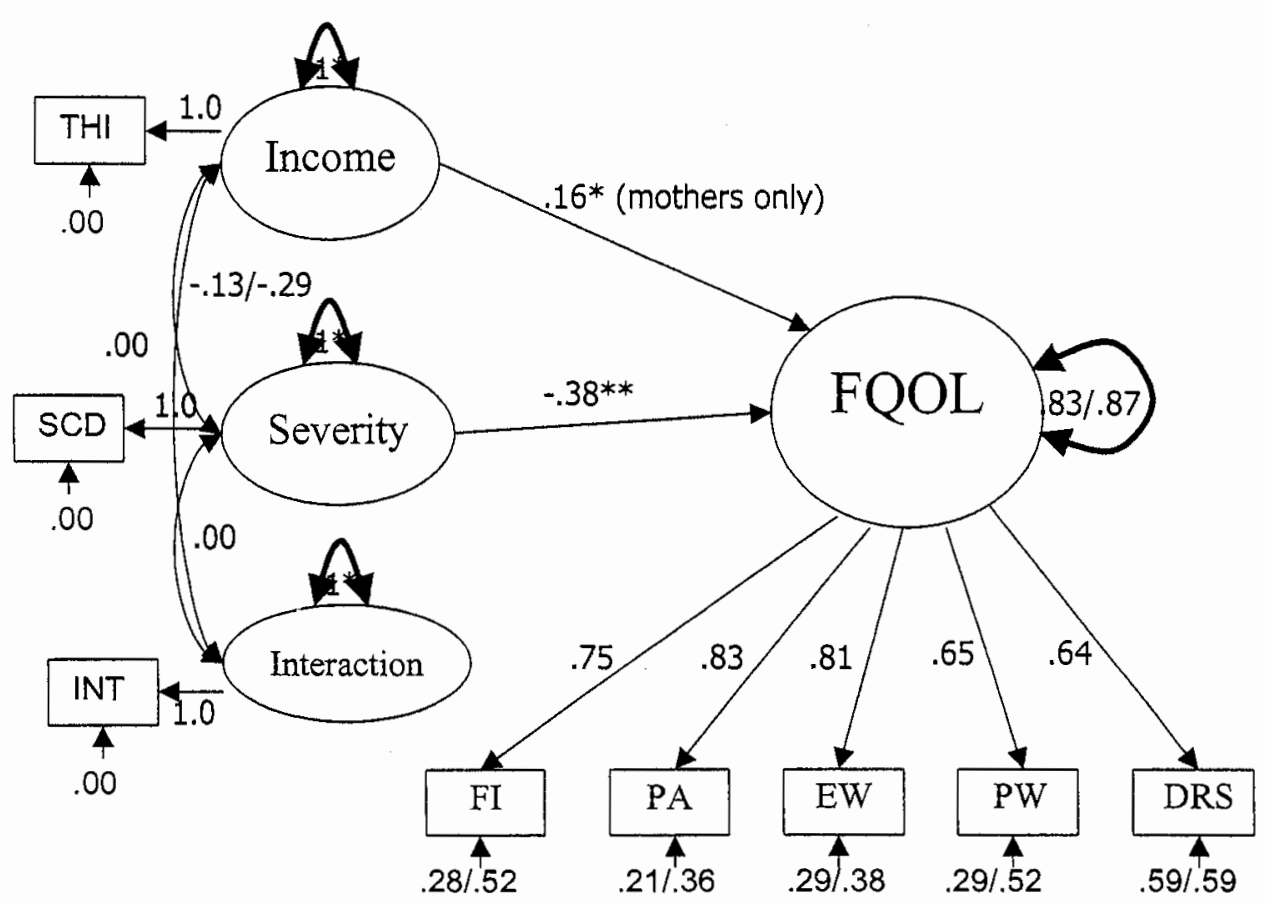

Figure 2. Interaction model of the predictors of mothers' and fathers' satisfaction with their FQOL.

in the middle income group, and $39 \%$ in the high income group. These distributions are different from the national 2002 income data reported by the U.S. Census ( $42 \%$ of households in the lower income group, $33 \%$ in the middle income group, and $25 \%$ in the high income group; U.S. Census Bureau, 2003). Given that the majority of participants in this study were from middleclass or upper-middle-class families, the results of this study may not be generalizable to all fathers and mothers who have children with special needs in Part B and C programs.

In addition, there is also a very skewed distribution with respect to the variable severity of disability in our sample. Demographic data for the fathers in this study indicate that in $57 \%$ of the children with disabilities, the disabilities were characterized as mild, $30 \%$ as moderate, $10 \%$ as severe, and $3 \%$ as very severe. Similarly, the mothers reported $61 \%$ of their children with disabilities as mild, $25 \%$ as moderate, $11 \%$ as severe, and $3 \%$ as very severe.

The other limitation of this study is that we had a relatively small sample size for fathers $(n=130)$. Given that the SEM approach usually needs a sufficient sample size $(n=200)$ for analysis, we recognize the limitations of our small sample size for fathers and caution against the generalization of our findings regarding fathers.

\section{Summary of Findings}

Three research questions were proposed to examine the associations between family income and severity of disability and fathers' and mothers' satisfaction ratings of their FQOL. The research questions were examined at two levels: (a) both family income and severity of disability as significant predictors of fathers' and mothers' assessment of their FQOL on the nonexistence of an interaction effect of family income and severity of disability and (b) family income and severity of disability as moderators for predicting fathers' and mothers' assessment of their FQOL on the existence of an interaction effect of family income and severity of disability.

\section{Family Income and Severity of Child's Disability as Significant Predictors}

Little has been revealed by the literature about the association between family income and severity of the child's disability and parents' satisfaction ratings of their FQOL.

We assumed that fathers and mothers of the highincome families and of families who have children with less severe disabilities would rate higher satisfaction with their FQOL. However, we found the results to be different for fathers and mothers. On the one hand, the findings reveal that both family income and severity of disability are significant predictors of mothers' satisfaction with their FQOL, which supports our assumption. The results are consistent with those of Scorgie, Wilgosh, and McDonald (1998); Vickers (1994); and Willoughby and Glidden (1995) regarding income and with those of Herman, Schofield, Murphy, and Singh (1994) and Smith, Innocenti, Boyce, and Smith (1993) regarding severity of disability. Thus, this study con- 
firmed the negative association between severity of disability and mothers' satisfaction with FQOL and the positive association between family income and mothers' satisfaction with FQOL. On the other hand, the findings show that severity of disability is a significant predictor of fathers' satisfaction with FQOL, which supports our assumption. But we found that family income is not a significant positive predictor of fathers' satisfaction ratings of $F Q O L$, which does not support out assumption. This result is inconsistent with that of Willoughby and Glidden (1995). However, we noted that family income is correlated relatively highly with the fathers' satisfaction ratings of FQOL despite our finding that the path between family income and fathers' satisfaction with their FQOL was not significant statistically. Considering the limitations of the study regarding the small sample size for fathers and the limited variation of family income variables in the father group (e.g., the majority of fathers in our sample are from upper-middle-income families), we are cautious about drawing the conclusion that family income is not a significant predictor of fathers' FQOL satisfaction ratings. Further research needs to be conducted to reexamine this issue.

\section{Interaction Effect of Family Income and Severity of Disability}

Given that previous research findings have suggested the intervening dynamics between family income and presence of disability in affecting family well-being and satisfaction (Fujiura \& Yamaki, 2000; Park, Turnbull, \& Turnbull, 2002), we assumed there would be a significant interaction effect of family income and severity of disability for predicting fathers' and mothers' satisfaction with their FQOL. However, our findings show that the interaction effect was not significant, indicating that severity of disability does not moderate the relationship between family income and fathers' and mothers' satisfaction with their FQOL or vice versa. The results of this particular research do not support our assumption and are inconsistent with one made by Park, Turnbull, and Turnbull (2002).

One should not ascribe too much to that consequence. Holmbeck (1997) pointed out that statistically significant moderator effects are difficult to detect and that the difficulty is "most likely to occur in studies where samples are relatively homogeneous because ail high and low values of the moderator and predictor may not be adequately represented" (p. 601). One of the limitations in this study is that we had a small sample size (especially for fathers, $\mathrm{n}=130$ ) and limited variation of data with respect to the variables of family income and severity of disability. In our sample, almost half of the fathers and mothers are from high-income families (about $45 \%$ of the total sample) and almost three fourths of the families have children with less severe disabilities (about $72 \%$ at mild and moderate levels). Thus, our failure to find an interaction effect may not mean that one does not exist; rather, it is very likely that we were unable to detect the interaction effect of family income and severity of disability. Further study is needed to explore the interactions of income and severity of disability in terms of their effects on FQOL.

\section{Implications for Future Research}

The fact that poverty (family income) and severity of disability significantly affect family quality of life has important implications for policy and research (Fujiura \& Yamaki, 2000; Park, Turnbull, \& Turnbull, 200\%;. This study has provided empirical evidence showing an association between family income and severity of disability and perceived FQOL for families whose children receive early childhood special services. Although our findings indicate that severity of disability is a stronger predictor than family income for both fathers and mothers in predicting their satisfaction with FQOL, we do not yet know the underlying dynamics behind this finding. Cummins and Baxter (1997) noted that caregiving burden, which is closely associated with the severity of child's disability, might be an influential factor in parents' assessment of their family well-being. However, this assumption does not take into account the fact that families who have children with more severe needs often are eligible to receive more resources and more intensive services and support. Similarly, families who fall below the poverty level are often eligible for additional services and supports that are unavailable to families who may have slightly higher incomes but who nevertheless cannot afford to purchase some services. Thus, caregiving burden derived from the needs of a child with a disability does not seem by itself to be a sufficient explanation of the effect of the severity of a child's disability on FQOL. Future tesearch should also take into account the levels and types of services the family is receiving as a potential mediating variable for understanding the impact of severity on FQOL (Bailey et al., 1998; Guralnick, 1997).

A further issue related to understanding the impact of severity relates to the ambiguous nature of the concept of "severity" itself. For example, research has shown that individuals with greater behavior problems could increase their mothers' level of burden and fathers' depressive symptoms (Essex, Seltzer, \& Krauss, 1999) and that the impacts of young children with autism and behavior problems on their family system and life are "pervasive and often disruptive" (Fox, Benito, \& Dunlap, 2002, p. 251). Given these findings, it is possible that a child with severe and multiple disabilities who has no mobility or language might actually be less challenging to a family than a child who is classified as having mild disabilities because she is highly verbal and mobile but who also experiences high rates of aggres. sive or other problem behavior. Future research should 
focus not on a broad construct like severity but rather on examining the relationship between more specific characteristics of the child's disability (e.g., behavior or medical conditions requiring continuous monitoring) and parents' satisfaction with their FQOL.

Surprisingly, the findings of this study reveal that there is no significant interaction effect between family income and severity of disability, providing no support to the assumption that an interaction effect between family income and severity of disability exists. Whether a combination of family income and severity of disability may affect FQOL differently has important implications for policy and practice. Future research to reexamine such an interaction effect of family income and severity of disability should be conducted and should include a sufficiently large and diverse sample and an inventory of services the family may be receiving as an additional mediating variable. Results from that research would help policy makers and professionals in their efforts to review and improve policies and provision of services to better support families who have children with disabilities. In this study, both income level and severity affected mothers' ratings of satisfaction with their FQOL, but only severity appeared to affect fathers' ratings to a significant degree. This finding may be due in part to the small sample size for fathers, which may have led to a failure of the differences to reach significance. Further study is needed with larger sample sizes to determine whether there is a substantial difference between mothers and fathers in the degree to which income affects their perceived satisfaction with FQOL. These further studies should also incorporate qualitative components to explore possible reasons for these observed gender differences.

\section{Implications for Policy and Practice}

The findings of this study indicate that family income and severity of disability are important predictors of mothers' and fathers' satisfaction with their FQOL (although income was not found to be statistically significant for fathers). Given the limitations of this study related to the limited representativeness of our sample with regard to the variables of family income and severity of disability, skewed distribution with respect to the variable of severity of disability, and the relatively small sample size for fathers, policy implications at this point are premature. If the findings of this study are replicated in future research that overcomes the limitations that we experienced, we believe that there will ultimately be policy relevance concerning the extent to which income and severity of disability predict FQOL satisfaction.

We anticipate future policy relevance of the questions addressed in this study within federal and state policy-making arenas. At both the federal and state levels, policy leaders confront increasing claims by the disability community to increasingly scarce resources, especially within the federal/state Medicaid and Supplemental Security Income programs under Titles XIX and XVI of the Social Security Act. Currently, eligibility for those programs depends on both the severity and the income level of the claimant. The data from future research studies focusing on the questions posed in this initial study will inform the debate about eligibility to financial resources and services.

What remains clear from these data and other studies (Park, Turnbull, \& Turnbull, 2002) is that poverty itself permeates several domains of FQOL. Furthermore, severity of disability has an overwhelmingly negative impact on various aspects of FQOL (Cummins \& Baxter, 1997). It is for these reasons that low-income families who have children with severe disabilities qualify for Medicaid and SSI benefits.

Similarly, it is for these and other reasons that service coordination and effective partnerships among families, professionals, and service systems are core concepts of disability policy and effective responses to the dual challenges of poverty and severity of disability (Park, Turnbull, \& Turnbull, 2002; Turnbull, Beegle, \& Stowe, 2001).

It is appropriate to put the results of this and other studies into larger policy contexts. One such context is the "competing equities" context: the increasing claims by some people (e.g., families who have children with severe disabilities) inevitably will conflict with the claims of other people (families who experience poverty and who have children with mild disabilities) to federal and state resources. The question that underlies the welfare reform initiative of the late 1990s (Ticket to Work and Work Incentives Improvement Act of 1999; Personal Responsibility and Work Opportunity Act of 1996) and recent attempts to curb the seemingly enlarging populations of those who have disabilities (Finn, Rotherman, \& Hokanson, 2001; Sutton v. United Air Lines, 1999; Turnbull \& Stowe, 2001) is simply this: Who is a "worthy" beneficiary and by what criteria should "worth" be judged?

Determining "worthy" beneficiaries must ultimately address the policy-relevant question of whether families who are raising a child with a disability have lower satisfaction with FQOL than families of typically developing young children. Future research needs to address this question, given that more than $80 \%$ of all persons identified as having intellectual disabilities, including about two thirds of adults, reside within their family home (Jaskulski, Lakin, \& Zierman, 1995; Larson, et al., 2001). Thus, implementing our nation's policies related to community inclusion, independence, and productivity hinges on the willingness and capability of families to continue to provide exceedingly high levels of support to their members with intellectual disabilities. In 2000 , states spent $\$ 1.05$ billion to assist families of persons with intellectual disabilities. Although this figure represented a $104 \%$ increase from the four pre- 
vious years, it still is only $4 \%$ of the total spending for all developmental disability services and, notably, the figure excludes expenditures under SSI (Braddock, Hemp, Parish, Rizzolo, \& Pomeranz, 2002; Parish, Pomeranz-Essley, \& Braddock, 2003). We have been unsuccessful in locating literature that provides an empirical basis for setting the eligibility requirements for various forms of family support, and the variability of federal and state policies reflects the lack of consensus about the most equitable way to distribute limited resources. For example, Federal Medicaid and SSI policies do limit eligibility by reason of income. However, family support programs at the state level may give priorities on the basis of severity, income, or some other means such as a lottery. Whether these criteria, which establish the priorities of worthiness and thus settie the competing equities issue, should be retained is the question to be resolved in future research to establish more empirical bases for these policy decisions.

The National Goals Conference sponsored by The Arc of the United States, in collaboration with 40 public and private organizations in the disability field, identified the policy promises that the United States has made to its citizens with intellectual disabilities and their families. One of 12 groups focusing on policy goals and related current knowledge bases was the Family Life Group. That group identified the overarching national policy goal in the disability field related to family life to be as follows: "To support the caregiving efforts and enhance the quality of life of all families so that families will remain the core unit of American society" (Keeping the Promise, 2003, p. 28). This initial research study is the beginning of a long-term effort to influence policy decisions based on family outcomes.

In conciusion, this study represents our efforts in exploring empirically the associations between family income and severity of disability and fathers' and mothers' assessments of FOOL. The results highlight that both family income and severity of disability are important predictors of parents' satisfaction with their FQOL, with severity of disability a stronger predictor in comparison with family income. The results of this study have important implications for future research, policy, and practice in early childhood programs, as well as in programs at later life span stages.

\section{References}

Abidin, R. R. (1995). Parenting stress index: professional manual (3rd ed.). Odessa, FL: Psychological Assessment Resources, Inc.

Aiken, L. S., \& West, S. G. (1991). Multiple regression: testing and interpreting interactions. Newbury Park, CA: SAGE Publications, Inc.

Bailey, D. B., McWilliam, R. A., Darkes, L. A., Hebbeler, K., Simeonsson, R. J., Spiker, D., et al. (1998). Family outcomes in early intervention: a framework for program evaluation and efficacy research. Exceptional Children, 64(3), 313-328.

Baker, B. L., McIntyre, L. L., Blacher, J., Crnic, K., Edelbrock,
C., \& Low, C. (2003). Pre-school children with and without developmental delay: behaviour problems and parenting stress over time. Journal of Intellectual Disability Research, 47(4-5), 217-230.

Beiderman, J., Miberger, S., Faraone, S. V., Kiely, K., Guite, J., Mick, E., et al. (1995). Family-environment risk factors for attention-deficit hyperactivity disorder. Archives of General Psychiatry, 52, 464-470.

Blacher, J., Nihira, K., \& Meyers, C. E. (1987). Characteristics of home environment of families with mentally retarded children. Comparison across levels of retardation. American Journal on Mental Retardation, 91, 313-320.

Braddock, D., Hemp, R., Parish, S., Rizzolo, M. C., \& Pomeranz, A. (2002). State of the states in developmental disabilities: 2002 study summary. Boulder, CO: University of Colorado, Department of Psychiatry and Coleman Institute for Cognitive Disabilities.

Bristol, M. M., Gallagher, J. J., \& Schopler, E. (1988). A developmental perspective on stress and coping in families of autistic children. In J. Blacher (Ed.), Severely handicapped young children and their families: research in review (pp. 91-134). New York: Academic Press.

Brown, I., Anand, S., Fung, W. L., Isaacs, B., \& Baum, N. (2003). Family quality of life: Canadian results from an international study. Journal of Developmental and Physical Disabilities, 15(3), 209-230.

Byrne, B. M. (1998). Structural equation modeling with LISERAL, PRELIS, and SIMPLIS: basic concepts, applications, and programming. Mabwah, NJ: Lawrence Erlbaum Associates.

Cummins, R. A., \& Baxter, C. (1997). The influence of disability and service delivery on quality of life within families. International Journal of Practical Approaches to Disability, $21(3), 2-8$.

Donovan, A. (1988). Family stress and ways of coping with adolescents who have handicaps: maternal perceptions. American Journal on Mental Retardation, 92, 502-509.

Dunst, C. J., \& Bruder, M. B. (2002). Valued outcomes of service coordination, early intervention, and natural environments. Exceptional Children, 68(3), 361-375.

Dunst, C. J., Jenkins, V., \& Trivette, C. M. (1984). Family Support Scale: reliability and validity. Journal of Individual, Family and Community Wellness, 1, 45-52.

Dunst, C. J., \& Trivette, C. M. (1988). Support Functions Scale. In C. J. Dunst, C. M. Trivette, \& A. G. Deal (Eds.), Enabling and empowering families: principles and guidelines for practice (pp. 143-146). Cambridge, MA: Brookline Books.

Elder, G., Nguyen, T., \& Caspi, A. (1985). Linking family hardship to children's lives. Child Development, 56, 361-375.

Essex, E. L., Seltzer, M. M., \& Krauss, M. W. (1999). Differences in coping effectiveness and well-being among aging mothers and fathers of adults with retardation. American Journal of Mental Retardation, 104(6), 545-563.

Finn, C. E., Rotherman, A. J., \& Hokanson, C. R. (Eds.). (2001). Rethinking special education for a new century. Washington, DC: Progressive Policy Institute and Thomas B. Fordham Foundation.

Floyd, F. J., \& Gallagher, E. M. (1997). Parental stress, care demands, and use of support services for school-age children with disabilities and behavior problems. Family Relations, 46(4), 359-371.

Fox, L., Benito, N., \& Dunlap, G. (2002). Early intervention with families of young children with autism and behavior problems. In J. M., Lucyshyn, G., Dunlap, \& R. W. Albin (Eds.), Families and positive behavior support: addressing problem behavior in family contexts (pp. 251-266). Baltimore, MD: Paul H. Brookes.

Friedrich, W. N., Greenberg, M. T., \& Crnic, K. A. (1983). A 
short-form of the Questionnaire on Resources and Stress. American Journal of Mental Deficiency, 88, 41-48.

Frey, K. S., Greenberg, M. T., \& Fewell, R. R. (1989). Stress and coping among parents of handicapped children: a multidimensional approach. American Journal on Mental Retardation, 94, 240-249.

Fujiura, G. T., \& Yamaki, K. (2000). Trends in demography of childhood poverty and disability. Exceptional Children, 66, 187-199.

Guralnick, M. J. (Ed.). (1997). The effectiveness of early intervention. Baltimore: Brookes.

Haldy, M. B., \& Hanzlik, J. R. (1990). A comparison of perceived competence in childrearing practices between mothers of children with Down syndrome and mothers of children without delays. Education and Training in Mental Retardation, 25, 132-141.

Hanson, M. J., \& Carta, J. J. (1996). Addressing the challenges of families with multiple risks. Exceptional Children, 62(3), 201-212.

Hanson, M. J., \& Hanline, M. F. (1990). Parenting a child with a disability: a longitudinal study of parental stress and adaptation. Journal of Early Intervention, 14, 234-248.

Heal, L. W., \& Sigelman, C. K. (1990). Methodological issues in measuring the quality of life of individuals with mental retardation. In R. Schalock \& M. J. Bogale (Eds.), Quality of life: perspectives and issues (pp. 161-176). Washington, DC: American Association of Mental Retardation. (ERIC Document Reproduction Service No. ED 323 698)

Herman, H., Schofield, H., Murphy, B., \& Singh, B. (1994). The experiences and quality of life of informal caregivers. In J. Orley \& W. Kuyken (Eds.), Quality of life assessment: international perspectives (pp. 131-150). Berlin: SpringerVerlag.

Holmbeck, G. N. (1997). Toward terminological, conceptual, and statistical clarity in the study of mediators and moderators: examples from the child-clinical and pediatric psychology literatures. Journal of Consulting and Clinical Psychology, 65(4), 599-610.

Jaskulski, T., Lakin, K. C., \& Zierman, S. A. (1995). A resource for state policy makers. Washington, DC: President's Committee on Mental Retardation.

Joreskog, K., \& Sorbom, D. (1993). LISREL VIII. Chicago: Scientific Software.

Kazak, A. E., \& Clark, M. (1986). Stress in families of children with myelomeningocele. Developmental Psychology, 21, 768-773.

Keeping the promise: Findings and recommendations: January 2003 Invitational Conference (2003). Washington, DC: The Arc of the United States.

King, S. M., Rosenbaum, P. L., \& King, G. A. (1996). Parents' perceptions of caregiving: development and validation of a measure of processes. Developmental Medicine and Child Neurology, 38, 757-772.

Kline, R. B. (1998). Principles and practice of structural equation modeling. New York: The Guilford Press.

Larsen, D. L., Atkisson, C. C., Hargreaves, W. A., \& Nguyen, T. D. (1979). Assessment of client/patient satisfaction: development of a general scale. Evaluation and Program Planning, 2, 761-774.

Larson, S. A., Lakin, K. C., Anderson, L. L., Kwak, N., Lee, J, H., \& Anderson, D. (2001). Prevalence of mental retardation and developmental disabilities: estimates from the 1994/1995 National Health Interview Disability Supplements. American Journal on Mental Retardation, 106(3), 231-252.

Little, T. D. (1997). Mean and covariance structures (MACS) analyses of cross-cultural data: practical and theoretical issues. Multivariate Behavioral Research, 32, 53-76.
Little, T. D., Hoffman, L., Bovaird, J. A., \& Widaman, K. F. (2004). On the merits of orthogonalizing curvilinear and interaction terms: Implications for modeling interactions among latent variables. Manuscript submitted for publication.

Mahoney, G., O'Sullivan, P., \& Dennebaum, J. (1990). Maternal perceptions of early intervention services: a scale for assessing family-focused intervention. Topics in Early Childhood Special Education, 10(1), 1-15.

McKinney, B., \& Peterson, R. A. (1987). Predictors of stress in parents of developmentally disabled children. Journal of $P e$ diatric Psychology, 12, 133-150.

Meredith, W. (1993). Measurement invariance, factor analysis and factorial invariance. Psychometrika, 58, 525-543.

Parish, S. L., Pomeranz-Essley, A., \& Braddock, D. (2003). Family support in the United States: financing trends and emerging initiatives. Mental Retardation, 41(3), 174-187.

Park, J. (2001). How to define and measure outcomes of early intervention: An examination of family quality of life. Unpublished doctoral dissertation, University of Kansas, Lawrence.

Park, J., Marquis, J., Hoffman, L., Turnbull, A., Poston, D., Mannan, H., et al. (2003). Assessing the family quality of life as the service outcome. Journal of Intellectual Disability Research, 47(5), 367-384.

Park, J., Turnbull, A., \& Turnbull, H. R. (2002). Impacts of poverty on quality of life in families of children with disabilities. Exceptional Children, 68(2), 151-170.

Personal Responsibility and Work Opportunity Act (P.L. 10589), 42 U.S.C. Secs. 620 et seq., 629, 670 et seq., and 1396a and $1396 \mathrm{~d}$.

Poston, D., Turnbull, A., Park, J., Mannan, H., Marquis, J., \& Wang, M. (2003). Family quality of life: a qualitative inquiry. Mental Retardation, 41(5), 313-328.

Scorgie, K., Wilgosh, L., \& McDonald, L. (1998). Stress and coping in families of children with disabilities: an examination of recent literature. Developmental Disabilities Bulletin, $26(1), 22-42$.

Seltzer, M. M., \& Krauss, M. W. (1989). Aging parents with adult mentally retarded children: family risk factors and sources of support. American Journal on Mental Retardation, 94, 303-312.

Shaw, D. S., \& Emery, R. E. (1987). Parental conflict and other correlates of the adjustment of school-age children whose parents have separated. Journal of Abnormal Child Psychology, 15, 169-281.

Smith, T. B., Innocenti, M. S., Boyce, G. C., \& Smith, C. (1993). Depressive symptomatology and interaction behaviors of mothers having a child with disabilities. Psychological Reports, 73, 1184-1186.

Spanier, G. B. (1976). Measuring dyadic adjustment: new scales for assessing the quality of marriage and similar dy ads. Journal of Marriage and the Family, 38, 15-28.

Sutton v. United Air Lines, 527 U.S. 471 (1999).

Ticket to Work and Work Incentives Improvement Act of 1999 (P.L. 106-170), 42 U.S.C. Secs. 1320b-19, 1396 et seq.

Turnbuil, A. P., Marquis, J. G., Hoffman, L., Poston, D., Mannan, H., Wang, M., et al. (2004). A new tool for assessing family outcomes: psychometric evaluation of the family quality of life scale. Manuscript submitted for publication.

Turnbuil, A. P., \& Turnbuil, H. R. (2001). Self-determination for individuals with significant cognitive disabilities and their families. Journal of the Association for Persons with Severe Handicaps, 26(1), 56-62.

Turnbull, A., Turnbull, H. R., Agosta, J., Erwin, E., Fujiura, G., Singer, G., et ai. (2003). Family life: leave no family behind. In Keeping promises: findings and recommendations of invitational conference on national goals, state of knowledge and research agenda for persons with intellectual and 
developmental disabilities. Washington, DC: The Arc and AAMR.

Turnbull, H. R., Beegle, G., \& Stowe, M. S. (2001). The core concepts of disability policy affecting families who have children with disabilities. Journal of Disability Policy Studies, 12(3), 133-143.

Turnbull, H. R., \& Stowe, M. J. (2001). Classification, social contracts, obligations, civil rights, and the Supreme Court. Remedial and Special Education, 22(6), 374-382.

U. S. Census Bureau. (2003). Income in the United States: 2002. Current Population Survey (CPS). Retrieved April 11, 2004 from http://www.census.gov/prod/2003pubs/p60221.pdf

Vickers, H. S. (1994). Young children at risk: differences in family functioning. Journal of Educational Research, 87, 262-270.
Vosler, N. R., Green, R. G., \& Kolevzon, M. S. (1987). The structure and competence of family units: implications for social work practice with families and children. Journal of Social Service Research, 9, 1-16.

Willoughby, J. C., \& Glidden, L. M. (1995). Fathers helping out: shared childcare and marital satisfaction of parents of children with disabilities. American Journal on Mental Retardation, $99(4), 399-406$.

Yau, M. K., \& Li-Tsang, C. W. (1999). Adjustment and adaptation in parents of children with developmental disability in two-parent families: a review of the characteristics and attributes. British Joumal of Developmental Disability, 45(1), $38-51$.

Received: May 11, 2004

Accepted: September 4, 2004

Editor in Charge: George H. S. Singer

This research was supported by a grant from the National Institute on Disability and Rehabilitation Research to the Beach Center on Disability, Grant \#H133B031133. 